\title{
Sequential Stepladder in the Development of Grounded Theory: Narrative Review
}

\author{
Balasubramanian $\mathrm{N}^{1}$, Thereza Mathias ${ }^{2}$ \\ ${ }^{1}$ Professor Cum Principal, Ambika college of Nursing, Mohali, $\mathrm{Pb}$. \\ ${ }^{2}$ Professor, Laxmi Memorial college of Nursing, Mangalore, Karnataka.
}

Abstract

\section{$>$ Background:}

Grounded theory is a method in qualitative research. Development of grounded theory is increasingly popular with medicine, nursing and health science researchers. It is a multifaceted and is in due course cultured during put into practice rather than direction but there are problems with how the methodology is being used. It is the generation of emergent theory from empirical data i.e., to build up a set of ideas and are incorporated and hypotheses in an incorporated theory that describes actions in any substantive area.

\section{Aim:}

A sequential step in the process of a grounded theory is explored in this paper. The collected data of real life situations will be analyzed and new theory will be generated relevant to the research problem.

\section{Methodology:}

The foundation of grounded theory generation is establishment data as it is from real life situation, not from suggestions, deductions, injustice inference, prejudice, or the association of ideas. Coding is done and new data will be collected continuously till the researcher feels that theoretical saturation has been reached.

\section{$>$ Data Collection Methods:}

Various data collection methods may be used to collect the data. Interview is the common technique used in grounded theory whereas participant observation, service log reports or help desk emails also used.

\section{$>$ Conclusion:}

Sequential way is used to develop different concepts that clarify psychosocial feelings of an individual experienced same type of the phenomenon under investigation. Researcher move towards query and theory come out with careful analysis.

Keywords:- Grounded Theory, Qualitative Research, Sequential Steps.

\section{INTRODUCTION}

Grounded theory was generated by Glaser and Strauss. The core plunge is to develop theories regarding societal observable fact. It is to develop higher level understanding that is "grounded" in or derived from a systematic analysis of data ${ }^{1}$. It is suitable when the study of social communications or experience aspire to clarify a development, not to investigate or authenticate an existing theory. Rather, the theories come out through cautious investigation of the information ${ }^{2}$. In grounded theory the researchers use to develop a theory inductively from data. In grounded theory topic is little known, the main aim of grounded theory study is to investigate all-round and to generate a theory truthfully based on the data as different of earlier research ${ }^{4}$. Sometimes, grounded theory is employed in advanced topic too.

\section{* Sequential steps theory is as follows: \\ $>$ Research initiation \\ $>$ Data selection \\ $>$ Data collection \\ $>$ Data analysis \\ $>$ Data synthesis \\ $>$ Generation of theory}

A sequential step involved in the process of grounded

\section{A. Research Initiation}

Glaser and Strauss the great pioneer of grounded theory, although they offer some thoughtful remarks about research problems; they do not give the matter systematic attention. Grounded theory is an explorative in nature; it does not begin from existing theory and pre-defined concepts. Begin the grounded theory with an assumption that participants share a problem situation, which they may or may not clear. There won't be any hypothesis, the center is to determine the key concerns about what is occurrence in the research situation and construct theory from the opinion. Initially the idea may look unclear but after data collection it gives shape for the research under study. Whatever the area of interest, the aim to explore and to seek out the situation as it is. As a researcher state the research problem clearly and it should provide road map of the study. However, it is typically data driven and therefore the topic or the statement of the study is sprouting, the research questions may be hard to pin down early on in the study. In addition, the inquiry is obliged to be supple and open-ended to permit the theory to build up. It be supposed to be wide 
area of interest to do sequential inquiry to be carry out of all the aspects of a fact in depth ${ }^{5}$.

\section{B. Data selection}

The data selection depends on nature of the investigation. The most important goal in data selection of grounded theory is the determination of appropriate data type, source, and instrument(s) that allow investigators to adequately answer research questions. Theoretical and purposive samplings are used to select the subjects ${ }^{6}$.

\section{Sampling}

In this grounded theory, the samples are not recruited through randomization. Here for the development of grounded theory participants or samples are recruit who are experiencing the nature under investigation. The sampling technique which is used in this approach is called as theoretical sampling technique. Glaser defined theoretical sampling as "the process of data collection for generating theory whereby the analyst jointly collects, codes, and analyzes the data and decides what data to collect next and where to find the data, in order to develop his/her theory as it emerges" $"$. Theoretical sampling is different from purposive and selective sampling generally exercised in qualitative research ${ }^{7,8}$. Theoretical sampling an important method of data collection and analysis, in various articles of grounded theory the author mentioned purposive sampling techniques. The data will be collected from the samples till saturation is reached ${ }^{9}$.

\section{Data collection}

Data gathered as participant observation, unstructured interviews, or other written documents or a combination of some methods ${ }^{10}$. The researchers use interview for generating new theory. The researcher to collect the data and coding will be done further analyze data at the same time $^{10}$. This process allows the researcher to evolve richer data where needed. Indeed, simultaneous. Researchers generally uses tape-record interviews or write out their conversation (verbatim) ${ }^{9}$. Interviewing techniques is often followed in grounded theory to collect the data. In grounded theory generation center of researcher is not to collect the data simply, it should be focus on to generate theory from chosen data ${ }^{11}$.

\section{E. Data analysis}

Data analysis, itself has different sequential steps.

The steps of data analysis in grounded theory are:

- Transcribe data

- Open coding

- Axial coding

- Selective coding

- Writing memo

\section{$>$ Transcribe Data}

After collecting the data, it should be write it down by listening to tapes or reading the data line by line, it is called as transcribe data $^{12}$. This is foremost work which is delegated require close observation, repeated listening or watching ${ }^{13}$. All the contents are to be written exactly without omitting single content. Next footstep in grounded theory after transcribe data is coding of data, which is essential in the analysis.

\section{Open Coding}

After reading line by line the data are put up into simplest form as much as possible, examined for universal phenomenon, and sorted into categories ${ }^{14}$. To build concepts in data without any limitation meaning, ideas, thoughts are to be analyzed. In open Coding, data are filtered for labeling concepts, defining and developing categories based on their properties and dimensions ${ }^{15}$. It should be clear and concise to move forward for next step axial coding ${ }^{16}$.

\section{Axial Coding}

As the intermediate step, data are reassembled based on logical connections between categories. Four analytical steps are require in axial coding: 1 . recurrently connecting sub categories to categories, 2. Putting side by side look on categories with collected data 3. explaining properties and dimensions and 4 . investigating different phenomenon. In axial coding, grounded theory process starts and dvelop ${ }^{19}$.

\section{Selective Coding}

Selective coding is a third stage of analysis in the grounded theory, the "core" category is determined and the relationships between it and secondary categories are posited. Here the scrutinized data are reconstructed and relates categories and core major categories thus building and purifying theoretical assert ${ }^{20}$.

\section{Writing Memo}

Memos build up as on paper thoughts or proceedings regarding idea and their association ${ }^{22}$. Memos adjoin to the trustworthiness and credibility of qualitative grounded theory research and offer a documentation of the sense obtained from the data. There are no hard and fast rules to be followed in memo. Memos develop as the research carry on and may differ significantly in method and approach ${ }^{22}$.

\section{F. Data synthesis}

Data synthesis includes the process of merging and reducing core categories, core patterns, and themes to facilitate generation of higher level theory and explanations. After the memos are arranged, which is the key to formulate the theory, new ideas are emerged. Review the literature to bring out the quality output of the developing theory ${ }^{23}$.

\section{G. Theory generation}

A grounded theory is straightly connected to the data from which it has been generated; it is therefore grounded in the data. Substantive and formal theories are the two types well known. Substantive theories afford a theoretical explanation for a particular area whereas formal theories are more abstract and provide a theoretical dealing of a generic issue ${ }^{5}$. The majority of grounded theories are substantive theories as they focus on particular problems in a specific, substantive area ${ }^{22}$. 
Comparisons of Glaserian and Straussian Grounded Theory ${ }^{24}$.

\begin{tabular}{|c|c|}
\hline GLASERIAN & STRAUSSIAN \\
\hline Begins with no idea about the phenomenon & Contain some idea to begin \\
\hline Starting with unbiased query & Explanation of situation \\
\hline Build up of a conceptual theory & $\begin{array}{c}\text { Recognizing variables and relationships obtained from } \\
\text { methods and Tools }\end{array}$ \\
\hline Recognizing variables and relationships obtained from the data & The theory is interpreted by an observer \\
\hline The theory is grounded in the data & The subjects are passive. \\
\hline The subjects are active & Data is structured to reveal the theory \\
\hline Data reveals the theory &
\end{tabular}

\section{APPLICATION OF GROUNDED THEORY IN HEALTH SCIENCES}

Social sciences department uses development of grounded theory whereas medical, nursing and other health science departments started developing grounded theories recently. Medical, nursing and health education concentrates the areas of instruction, training, program development and assessment of research studies to develop grounded methodology. Hardly, small number of papers on grounded theory in medical and nursing education ${ }^{24}$. In qualitative research, particularly case study is used mainly in medical and nursing department whereas ethnography research also used medical education ${ }^{24}$.

\section{CONCLUSION}

This paper effort to make clear about sequential steps to be followed in grounded theory. Few studies are found related to grounded theory methodology in health sciences. Despite quantitative measurements, feelings, emotions, opinion cannot be always quantitative. Hence, qualitative research is required to assess the feelings, emotions and opinions. Equal priority is to be given for qualitative research as of quantitative.

\section{REFERENCES}

[1]. GlaserB,StraussA.The discovery of grounded theory: strategies forqualitative research. Chicago: Aldine, 1967.

[2]. Cleland JA. The qualitative orientation in medical education research. Korean J Med Educ. 2017 Jun; 29(2): 61-71.Published online 2017 May 29. doi: $10.3946 / \mathrm{kjme} .2017 .53$

[3]. Lingard L,Albert M,Levinson W. Grounded theory, mixed methods, and action research. BMJ 2008;337:a567 doi:10.1136/bmj.39602.690162.47

[4]. Ullah H. rounded Full Captions | Hafiz Ullah Academia.edu. available at: Search Results www.academia.edu , Grounded_Full_Captions.

[5]. Strauss AL, Corbin JM. Basic of qualitative research: Grounded theory procedures and techniques. Newbury Park (CA): Sage; 1990.
[6]. Foley $G$ and Timonen V. Using Grounded Theory Method to Capture and Analyze Health Care Experiences. Health Services Research (August 2015) 50:4 DOI: 10.1111/1475-6773.12275.

[7]. Glaser B.G. Theoretical Sensitivity: Advances in the Methodology of Grounded Theory. Mill Valley (CA): Sociology Press. 1978.

[8]. Jeon YH. The application of grounded theory and symbolic interactionism. Scand J Caring Sci. 2004; 18: 249-56.

[9]. Tavakol M, Torabi S, Zeinaloo AA. Grounded theory in medical education research. Med Educ Online [serial online] 2006;11:30 Available from http://www.med-ed-online.org.

[10]. Strauss AL, Corbin JM. Basic of qualitative research: Grounded theory procedures and techniques. Newbury Park (CA): Sage; 1990.

[11]. Mason, J. Qualitative Researching. 2nd Edition, Sage Publications, London.2002.

[12]. Stern PN. Grounded Theory Methodology: Its Uses and Processes. Journal of nursing scholarship. February 1980. https://doi.org/10.1111/j.15475069.1980.tb01455.x

[13]. Bailey J. First steps in qualitative data analysis: transcribing.Fam. Pract. 2008. 25:127-131, First published 27 Feb 2008; doi:10.1093/fampra/cmn003.

[14]. Birks, M., \& Mills, J. Grounded theory: A practical guide. London, England: Sage.2015.

[15]. Polit \& Beck. Nursing research: principles and methods

[16]. Glaser, B. G. The Grounded Theory Perspective: Conceptualization Contrasted with Description. Mill Valley, CA, Sociology Press. 2001.

[17]. Strauss, A. \& Corbin, J. Basics of Qualitative Research: Grounded Theory Procedures and Techniques. Newbury Park, CA: Sage Publications. 1990.

[18]. Brown, Stevenson, Troiano and Schneider. Exploring complex phenomena: Grounded theory in student affair research. Journal of college student development. 2002:43(2):173-83.

[19]. Douglas D. Inductive theory generation: A grounded approach to business inquiry . Electronic Journal of Business Research Methods, Volume 2 Issue 1 (2003) 47-54. 
[20]. Kaiser G and Presmeg N (eds.), Compendium for Early Career Researchers in Mathematics Education, ICME-13 Monographs, https://doi.org/10.1007/978-3030-15636-7_4

[21]. Strauss AL. Qualitative analysis for social scientists. New York: Cambridge University Press; 1987.

[22]. Charmaz K. Constructing Grounded Theory A Practical Guide Through Qualitative Analysis. SAGE Publications. 2006.

[23]. Pope, C., Mays, N., and Popay, J. Synthesizing Qualitative and Quantitative Health Evidence: A Guide to Methods. Maidenhead : Open University Press , 2007, £19.99 , ix+210pp . ISBN 9780335 219568 (pb), 9780335219575 (hb)

[24]. Harris I. Qualitative methods. In: Norman GR, van der Vleuten C, Newble D. International handbook of research in medical education. Boston (MA): Kluwer; 2002. p. 45-59. 